\title{
Visual Art and the Rhythm of Experience
}

Levin, Kasper; Roald, Tone; Funch, Bjarne Sode

Published in:

The Journal of Aesthetics and Art Criticism

DOI:

10.1111/jaac. 12647

Publication date:

2019

Document Version

Peer reviewed version

Citation for published version (APA):

Levin, K., Roald, T., \& Funch, B. S. (2019). Visual Art and the Rhythm of Experience. The Journal of Aesthetics and Art Criticism, 77(2), 281-293. https://doi.org/10.1111/jaac.12647

\section{General rights}

Copyright and moral rights for the publications made accessible in the public portal are retained by the authors and/or other copyright owners and it is a condition of accessing publications that users recognise and abide by the legal requirements associated with these rights.

- Users may download and print one copy of any publication from the public portal for the purpose of private study or research.

- You may not further distribute the material or use it for any profit-making activity or commercial gain.

- You may freely distribute the URL identifying the publication in the public portal.

Take down policy

If you believe that this document breaches copyright please contact rucforsk@kb.dk providing details, and we will remove access to the work immediately and investigate your claim. 


\section{Visual Art and the Rhythm of Experience}

\section{ABSTRACT}

The concept of rhythm is frequently used by art historians, critics, and philosophers as a way of describing central features of visual art. Since rhythm is generally considered to be a temporal phenomenon associated with music, it is far from clear how visual art, composed of fixed lines, figures, and color, can be associated with rhythmicity. Linked to a temporal ordering or structure in music, the notion of rhythm in visual art leads to a claim that the aesthetic aspect of a painting does not consist in, or emerge from, its spatial structures, but rather its temporal ordering of the visual field. Recently this account of rhythm in visual art has been criticized by philosopher Jason Gaiger, who argues that visual art does not comprise movement and therefore cannot be associated with a temporal rhythm. Through a discussion of temporality and rhythm in Edmund Husserl, Erwin Straus, and Henri Maldiney, this article maintains that rhythmicity is a central aspect of experiences with visual art. It is shown that the phenomenological account of rhythm in the experience of visual art is fundamentally linked to a different notion of time.

\section{RHYTHM IN VISUAL ART}

Rhythm in music can be defined as "everything pertaining to the time aspect of music as distinct from the aspect of pitch" (Rutherford-Johnson, Kennedy, and Kennedy 2013 in The Oxford Dictionary of Music) or "everything to do with both time and motion-with the organization of musical events in time" (Whittall 2011 in The Oxford Companion to Music). This idea goes back to the ancient Greek philosophers, for whom rhythm was considered as an ordering of movement or time (Williams 1911). In terms of these musical descriptions of rhythm as a fundamental temporal aspect, the question of the existence of rhythms or a rhythmic quality in experience depends on whether or not it makes sense to consider the experience as temporally constituted.

To modernist artists like Wassily Kandinsky, Paul Klee, and Paul Cézanne, the musical notion of rhythm became a central aspect of pictorial formation which was to be investigated artistically, because they saw it as giving form to movement. The attempt to represent movement in spite of a painting's stationary state was nothing new to visual art. Many artists throughout the Western history of art have attempted to visualize movement in figurative paintings. The Battle of San Romano (ca. 1435-1460) by Paolo Uccello, The Blind Leading the Blind (1568) by Pieter Bruegel the Elder, The Rape of the Sabine Women (ca. 1638) by Nicolas Poussin, The Raft of the Medusa (1819) by Théodore Géricault, and Ballet Rehearsal (1873) by Edgard Degas are just a few such treasures among many. This attempt to represent movement in figurative art culminated at the beginning of the twentieth century with the Futurists Movement. Inspired by Cubism and Eadweard Muybridge's serial photographs, they emphasized rhythm by visualizing movement in successive stages. $D y$ namism of a Dog on a Leash (1912) by Giacomo Balla and Nude Descending a Staircase (No. 2) (1912) by Marcel Duchamp are two celebrated examples. The introduction of abstract art, however, heralded a departure from visual references to the world and an attempt to reproduce an illusion of movement. In Concerning the Spiritual in Art ([1977] 1977) Kandinsky claims, 
A painter, who finds no satisfaction in mere representation, however artistic, in his longing to express his inner life, cannot but envy the ease with which music, the most non-material of the arts today, achieves this end. He naturally seeks to apply the methods of music to his own art. And from this results that modern desire for rhythm in painting, for mathematical, abstract construction, for repeated notes of colour, for setting colour in motion. $(1977,19)$

Kandinsky's sense of envy toward rhythm in music animated his ambition to go beyond representation and, through abstraction and nonrepresentational aspects of visualization, to reach out for a rhythm similar to music. In letting go of the figurative aspects as being the formative element of painting, he and other pioneers of modern art, such as Francis Picabia, Robert Delaunay, and František Kupka, were looking for new ways of acquiring form in their composition, which not only broke with the traditional representation but also reached out for an art directly linked to the artist's inner life.

A central notion for this trend was that the artist's task was to reveal new ways of sensing the world. A famous expression of this tendency is found in Klee's often-quoted comment: "Art does not reproduce the visible but makes visible" (1961, 76). In this view, painting moved toward revealing forces otherwise hidden from our everyday experience. Kandinsky also suggested that the primary hidden force that preoccupied the painters of this period was movement or setting color into motion. Through the notion of giving form to motion and sensing - fundamentally temporal aspects - these artists saw rhythm as central to the visual arts. Although inspired by rhythm in music, they saw no need to limit it to music. Rhythm, they argued, was essentially present in the visual arts through the rendering of movement and sensing.

To art critics and historians contemporary to the modernist era, rhythm often became a central feature in the description of movement in visual art. Art critic Roger Fry describes how Cézanne, in a landscape painting, "was able to give to the mountains, the houses, the trees, all their solid integrity, to articulate them in a clearly felt space and yet to sustain a rhythm of plastic movement almost unbroken from one end of the canvas to another" $(1951,94)$. Rhythm is a recurrent theme in Fry's description of Post-Impressionism, but also a phenomenon traced in its different expressions throughout the history of art. For example, Fry describes how rhythm is a quality in a drawing by Jean-Antoine Watteau that exposes the passage between Baroque and Roccoco painting $(1951,39)$ or how Géricault's drawings "recapture the grand rhythmic flow of the High Renaissance" (57). A similar appeal to rhythmic qualities can be seen in many descriptions by art historian Heinrich Wölfflin who, for example, describes the "fascinating rhythm" $(1950,216)$ of Rembrandt's Baroque etching Woman with the Arrow (1661) or the different qualities of rhythm exposed when comparing Titian's Venus of Urbino (1534) with Diego Velasquez's Rokeby Venus (1647-1651) (Wölfflin 1950, 169).

Visual artists' aspiration for movement and rhythm has continued throughout the twentieth century and up to the present day. Jackson Pollock is just one among many. He tried, like artists before him, to get away from traditional representation by pouring and spattering paint onto the canvas. Video, installation, and performance art are more recent attempts to introduce movement in visual art. By using media other than traditional painting they create new relationships between the artist, work, and audience in a similar attempt to manifest a living sensation through their art.

\section{CRITICAL ARGUMENT}

From a commonsense perspective it immediately appears paradoxical to argue that a paintingan inanimate spatial object-should give rise to the experience of a temporal aspect of a rhythmic character. In a recent critique of the use of rhythm in relation to experiences with visual art, philosopher Jason Gaiger critically asks, "Since rhythm is essentially durational, how can a stationary configuration of marks and lines be rhythmic?" (2018, 1). An immediate answer to this question could be to argue that since all perception takes place in time, it is not unreasonable to assume that rhythm could be a means of capturing precisely this temporal aspect of visual experience in the encounter with a work of art. However, what Gaiger argues is that nothing is actually gained from applying rhythm to the understanding of aesthetic experiences with paintings. His main argument against rhythm in the aesthetic experience of paintings is carried through by a simple contrasting of the 
temporal aspect of rhythm in music with the static or inanimate character of paintings. Not only is nothing to be gained from applying rhythm to paintings, the concept of rhythm loses its meaning if we apply it to paintings without any temporal reference, "for we would no longer have a way of marking the distinction between a spatial pattern and a rhythmic spatial pattern" (Gaiger 2018, 4). Given the immobile character of a painting, Gaiger infers that the only possibility of a rhythm in painting must necessarily be related to the temporal sequence of the saccadic movements of the beholder. In this context, Gaiger takes a definition of rhythm in Western music as "the establishment of a regular pulse or tactus and its subdivision into metrical units," and he challenges the possibility "for regularities in the visual organization of the work to structure attentional regularities in the perceptions of the viewer" $(2018,5)$. According to Gaiger, to talk about a rhythm in aesthetic experience of visual art would amount to a specific and reproducible sequential structure. As he asks rhetorically in relation to Sonia Delaunay's painting Rythme couleur no. 1076, (1939), "could I tap the rhythm out or move in time to it?" $(2018,4)$. On these premises, Gaiger analyzes different abstract and figurative paintings, convincingly showing that visual art most often lends itself to many different potential sequences of visual attention, which, in his view, reveals that applying rhythm to experiences of visual art does not contribute to our understanding. Although this could lead to the conclusion that paintings give rise to many different rhythms, Gaiger argues that this would deprive the notion of rhythm of its meaning as an identifiable temporal sequence. To further test the rhythm hypothesis, Gaiger refers to eye tracking studies of the relationship between the compositional structure of paintings and eye movements, which conclude that "the eye hardly ever moves systematically along a composition line from one end to the other" $(2018,16)$. Gaiger does acknowledge that some works of pictorial art can be rhythmic, but following the necessarily temporal notion of rhythm, paintings can only be associated to rhythm in particular cases in which the visual attention is guided by an extra-pictorial aid through a specific compositional sequential line-for example, an instruction by a critic or privileged knowledge of the artist's intentions.

Summing up Gaiger's critical argument, his skepticism toward rhythm in painting is due to his view that visual art is nonsequential, and since rhythm per definition is temporal and must be sequential, aesthetic experience of paintings cannot be rhythmic. In other words, due to the fundamental difference between the temporal nature of rhythm and the spatial nature of painting, rhythm cannot be a general feature of aesthetic experience in pictorial art, only a particular case of temporal guidance of the spatial element of visual experience. Accordingly, in Gaiger's account, temporal constitution of experience is understood in terms of linearly extended time or objective time, which, in relation to visual art, associates the temporal aspect to the measure of eye movements in the reception of works of art. To review this perspective, in the following section we contrast Gaiger's analysis of the temporal aspect in aesthetic experience to a phenomenological account.

\section{III}

\section{PHENOMENOLOGICAL RHYTHM}

Following the premises for the argument against rhythm in painting, Gaiger makes a rigorous and accurate point of analysis. As he points out, it would indeed be inconsistent to claim that a general feature of aesthetic experiences of pictorial art is rhythm in the same temporal account as in music. However, the question is whether this account of temporality and rhythm addresses the same aesthetic aspects of visual experience as, rhythmicity as referred to by the artists and theorists mentioned earlier, as well as the sources that Gaiger himself opposes. In the following we argue that Gaiger's notion of rhythm is not consistent with the concept of rhythm in experience as proposed by phenomenology.

From a phenomenological point of view, what is striking in Gaiger's critique is that his notion of experience is primarily connected to the object of experience and not the subject of experience. For example, when Gaiger writes, "Although the experience of viewing Delaunay's Rhythm Colour no 1076 unfolds over time, there does not seem to be anything inherent in the work itself that can guide or structure the viewer's experience so that the parts are viewed or apprehended in a specific sequence" $(2018,7)$. As this illustrates, when Gaiger refers to "a structure of the viewer's experience," this does not relate to any subjective account of experience, but rather to a set of objective structures of the beholder's eye movements. 
Accordingly, aesthetic experience must be explained by the formal objective elements in the subject's physiological conditions for perceiving the "visual properties" of the work of art. To experience a painting or having an aesthetic experience is reduced to simply viewing it or directing your eyes at it.

In a phenomenological perspective, what Gaiger describes is not subjective visual experience, but objective visual behavior based on physiological measures (eye tracking). As could be argued with Edmund Husserl's classical phenomenological concept of intentionality, Gaiger's approach does not bring us closer to rhythm as a phenomenon of subjective experience. In his essays, On the Phenomenology of the Consciousness of Internal Time (1991) and Analyses Concerning Passive and Active Synthesis (2001), Husserl used the musical phenomenon of a melody as the paradigm of our pre-reflective consciousness of time. Here, Husserl targets the apparent paradox of how we can perceive the temporal aspect of a continuously moving or changing object of consciousness such as a melody, since we only have direct perceptual access to the now phase. According to Husserl, the melody is possible because of a fundamental immanent time consciousness, which could be described as a "threefold structure" (Zahavi 2010, 321; Brough in Husserl 2001, xxxi) of intentionality. When we perceive a melody, the tone or the nontemporal now phase of a sensory content is always accompanied by the retention of past tones and the protension of anticipated tones. In short, what Husserl points out is that the present moment of experience never appears alone but is always given in an immanent experiential structure of temporality that connects the "now phase" to past and future moments. In this context, Husserl describes three different planes of temporality: objective time of appearances, immanent subjective or pre-empirical time of the sensuous acts of constituting multiplicities, and finally the absolute pre-phenomenal timeconstituting flow of consciousness (Husserl 1991, 77-80, 368-69; Zahavi 2010, 335). In the context of rhythm, what is central to Husserl's phenomenological description of temporality and the experience of a melody is that it introduces time as an immanent temporal aspect of consciousness different from the objective time of appearances. In Husserl's analysis of the melody, the structure of time consciousness provides qualitative unity to the extended continuity of passing impressions or objective time points of the moving melody. This model of inner time consciousness applies to all lived experience as Husserl considers time consciousness to be a pre-empirical and immanent aspect of self-awareness. The temporal aspect of music, here in the form of the melody, becomes the paradigm of how time gives unity to subjective experience or pre-reflective self-awareness. Time in this perspective amounts to a pre-reflective passive synthesis or a "lawful, fundamental regularity in the way in which sense is constituted, particularly, as a mode of sense-genesis" (Steinbock in Husserl 2001, xxxviii). Time as a passive synthesis is an experience of pre-givenness as foundation for active directedness of intentionality and consciousness.

Although Husserl primarily refers to the temporal aspects of the tonal sequences and only vaguely to rhythm in his descriptions of inner time consciousness, the consequence of his description reveals an immanent temporal aspect of pre-reflective subjective experience, which opens the possibility of another and more fundamental definition of rhythm. This more fundamental aspect of rhythm consists in its relationship to the pre-empirical constitutive or awakening force of affective unity of consciousness. As Husserl remarks, "[H]ow rhythmatizations arise ... shows an especially awakening force, and in the awakening, an affectively binding force for consciousness" $(2001,407)$. More specifically, if rhythm per definition is temporal, then Husserl's phenomenological analysis of inner time consciousness reveals a notion of pre-empirical flow or phenomenological time, which accommodates a phenomenological understanding of rhythm as a pre-reflective constitutive force central to what Husserl sometimes calls "affective communication" (2001, 229).

Unlike Gaiger's quantification of rhythm as a temporal object composed by a distribution of extended time points in visual space, rhythm in this phenomenological account relates to the constitutive aspect of affect in self-awareness and sense-genesis. Having established that a phenomenological notion of time consciousness accommodates the possibility of a description of rhythm different from the objective account of a sequence in extended space, the critical question is how this rhythm can be described as a general feature immanent to the experience of static 
forms of visual art. In the following section we address this question through the work of the phenomenologist Erwin Straus.

\section{RHYTHM AND THE UNFOLDING NOW OF SENSING}

Straus's work on rhythm and experience relates closely to Husserl's remarks on rhythmatization as an awakening or an "affectively binding force for consciousness" (2001, 417). But unlike Husserl's phenomenological concept of internal time consciousness, which only indirectly accommodates rhythm as an element of the pre-empirical constitutive aspects of experience and self-awareness, Straus more directly dedicates thinking to the concept of rhythm as a central unifying force in subjectivity.

Not far from Gaiger's observation, Straus argues that a visual rhythm produced with, for example, a sequence of light and colors can never attain the same "clear experience of rhythm" $(1966,10)$ as when one hears an articulated succession of tones. In other words, it is easier to experience rhythm through its clear expression in music than through its more subtle expression in visual objects. However, unlike Gaiger, this difference is not to be explained through any objective difference between optical and auditory elements or through the reduction of rhythms to sequences in objective time, but pertains instead to a phenomenological difference immanent to experience across different sense modalities. Specifically, in relation to the experience of rhythm in music and visual objects Straus writes:

This difference in the appearance of rhythm between optical and acoustical presentations is not based on any difference between acoustical and optical stimuli; it cannot be explained physiologically at all but can only be derived from the phenomena. To focus on physiological explanations here would be to ignore other highly significant differences. (1966, 10-11)

Thus, as a clear statement opposing Gaiger's optical operationalization of rhythm, Straus assigns the difference between visual and auditory rhythms to a significant emergent aspect of experience as such, which relates to the immanent role of movement in sensation. Here, rhythm is not particular or exclusive to the auditory sense modality but is rather coupled to the sense of movement as the "common sense" of all the senses-or that by which the different sense modalities communicate internally in experience. Subsequently, the reason why rhythm is experienced differently in painting and music is that the visual and the auditory domains are dominated by two fundamentally different aspects of sensation and subjectivity. As Straus argues, in visual space things appear to be separated in contours, which leads to a representational aspect of sensation. This, however, presupposes an already established subject-bject relationship in which visual objects present themselves to us in space as already given gestalts toward which we direct our perceptual attention. The world reveals itself to us in representational visual givens, which often leads to the replacement of the concept of sensation with sensuous representation. Although representational consciousness is indeed an adequate description of a particular function of subjective experience, Straus argues that this does not constitute the whole story about sensation and subjectivity. What is missing from the story is the emergence or constitution of space.

What occupies Straus is sensation as a primary relationship with the world that could be termed as one of his central texts, The Sense of the Senses (1965). The notion of a primacy of sensation as the fundamental and ontological element of subjectivity can be described as an attempt to approach the classical problem of unity of the senses in subjective experience or sensus communis. Going back to Aristotle, the problem of sensus communis refers to an ancient but still highly relevant discussion of how we can account for the integration or unification of our different sense modalities in a single subject of experience. In other words, what Straus is attempting to describe is the subject as an emergent unity that cannot be taken for granted in our descriptions of the experiential world, but must itself be explained. As he argues, in science and in everyday life, we take our capacity to see and describe the world for granted, but it is the task of psychology to thematize this. It is in this perspective that sensation becomes the critical locus of Straus's investigation, that is, the relationship between "the sensing subject and subject of sensation" (1963, 12). According to Straus, psychology and philosophy have primarily focused on the subject of sensation, which generally has reduced sensation to perception, so his differentiation is with the clear "intention to 
separate quite strictly sensing from perceiving" $(1963,13)$. In terms of his focus on sensing or sensation and movement, what is essential to this difference is, as Straus remarks, that "sensing has in itself the character of change, and thus a definite temporal structure" $(1963,18)$. It is this character of change, temporal structure, or movement immanent to sensation that is key to understanding the fundamental difference between hearing and vision as well as their relation to rhythm.

Apart from the perceptual and representational aspect in which we experience the visual objects as over there in front of us, as gestalts separated by contours, Straus argues that we also experience the world in its becoming in perpetual movement and temporal change. Vision is mostly experienced as a positioned and particular directedness where the subject must actively turn toward the object in order to experience it, whereas sound is experienced as a phenomenon moving toward the subject. In this way the visual domain appears moreover to be passive in front of the active subject, while the domain of sound and music appears as actively surrounding the subject directly. As Straus explains, "tone has an activity all its own; it presses in on us, surrounds, seizes, and embraces us. Only in a later phase are we able to defend ourselves against sound, only after sound has already taken possession of us, while in the visual sphere we begin to take flight before we have been prehended" $(1963,18)$. To Straus, the experience of sound exemplifies the emergent qualities and unity of sensing, as opposed to the distancing and separating qualities of perceiving. This differentiation also constitutes two separate but different relationships between sensation and movement, which schematically could be considered as the differentiation between moving and being moved (376).

In visual representation we see the movement or change of the object, but this already presupposes the permanence of the object in which the sense of movement or change is given to visual perception. Perception therefore does not reveal the process of how objective space and time are constituted. It is primarily in dance, sound, and music that we, according to Straus, more clearly experience a different aspect of sensation connected more directly to the experience of movement. In music, Straus argues, "the succession of tones brings the temporal character of its existence to the fore; its temporal differentiation differentiates time in turn. It is the autonomous existence of tone and its relatedness to time that endow its sounding rhythms with such rich significances [Prägnanz]" $(1966,10)$.

In music, tone and rhythm is experienced in a more intensive and direct way because the temporal aspect is foregrounded as a processual or direct unfolding relationship with the world. The point is that sound and music express a perpetual unfolding of time contemporary to the unfolding of the experiencing subject. The immediate propensity to animate us to move or become moved by the dancer's rhythmic movements testifies to the fundamental unifying aspect of primordial movement. Rhythm is the organizing principle that unifies sensing in an immanent connection to movement and time. Where the visual object can be said to be in time, an object in sound is always of time - that is, a perpetual unfolding of time. In listening to a piece of music the tones will create their own time through the perpetual unifying movement of the composition of themes, motifs, rhythms and melodies, whereas the painting, considered as a perceptual object, will always appear as a static capture of a movement in already unfolded temporal structure. As Straus explains, this is linked to a fundamental qualitative difference in the appearance of visual and auditory objects.

The colored object, we said, appears there, over against us, in a particular direction and at a particular limited and delimiting distance. Unlike a tone that approaches us, the color retains its place. To experience the color, we must turn toward it, look at it, actively master it. $(1966,15)$

This qualitative difference between visual objects and objects of sound is a paradigmatic expression of the distinction between sensing and sensation in what Straus respectively terms the pathic and the gnostic moments. By pathic moment he means "the immediate communication we have with things on the basis of their changing mode of sensory givenness" $(1966,12)$. In relation to movement, the pathic moment should be understood as the primordial vitality immanent to the appearances of the perceptual world. Thus, as opposed to the active directedness of our subjective experience, the pathic moment concerns the way that objects appears to move us in different ways. 
Consequently, beyond the perceptually given modes of visual and auditive objects, the pathic moment refers to the process of becoming or the existential mode of colors and sounds. It is important to note here that the changing mode of things - that is, how they move us - does not refer to the change of any features or properties of the object but is a question immanent to the unity of subjectivity in any perceptual act. As Straus argues, the senses of hearing, vision, touch, and so on do not simply provide sensory impressions that make color and sound to appear before us as perceptual given "at the same time that we perceive objects, we also sense the colors and tones, i.e., they take hold of us and influence us in a lawfully determinate way" $(1966,11)$.

Philosopher Renaud Barbaras portrays how Straus's originality consists in approaching "sensory experience from an existential point of view" (2004, 219). In Straus's work the paradigm of this existential aspect of sensation is primarily unfolded in the experience of music and dance. Consequently, what is most clearly experienced in the domain of sound, music, and expressive bodily movement is a sensation that cannot be reduced to its perceptual givens, because the primary temporal aspect of movement is a precondition for the unity of subject of sensation, that is, the unifying communication immanent to the senses. Immanent to the senses does not mean immanence reduced to the apprehension of one's own perceptual being, but movement as a presubjective condition of how something comes forth as being there. Rhythm in Straus's work therefore becomes a concept that refers to the presubjective or emergent unity of sensing that constitutes the structuring of movement in all the sense modalities.

The aesthetic concept of rhythm is here related to a more general idea of sensory and perceptual experience. When Straus refers to rhythm as an intermodal aspect immanent to sensation he is thinking specifically of the power of rhythms to elicit bodily movements corresponding directly to musical experience of sound. Rhythm is what structures movement, which is immanent to all the senses. Straus further extends this structuring feature of rhythm to the communication between the different senses. This structuring of movement and communication between the senses is the primordial role of rhythm as a cross-modal communication by which an I-world relationship is established. Straus considers the communication between the senses as a pre-conceptual mode of communication because it constitutes the pathic ground for subjectivity in our immediate encounter with appearances $(1966,12)$.

\section{TIME AND MOVEMENT IN THE LANDSCAPE}

Although Straus's description very clearly links his notion of the pathic dimension to objects of sound and music, the gnostic domination of the visual domain does not mean that vision is not grounded in a pathic moment or an unfolding now of sensing. Returning us to our main endeavor in the question of visual art, Straus argues that it is precisely in art that the pathic moment becomes an important aspect of expression, also in visual art: "Artistic activity is dependent on the pathic moment of the optical phenomenonreactively dependent down to the tiniest details of technique" $(1966,17)$. Straus mentions how, for example, Baroque painters aspired not to portray objects as juxtaposed in their paintings, and how, through manipulation of density, light, dimensions, the frame, chiaroscuro modeling, and so on, they reduced the contours through representations in the plane. In support of his claim Straus quotes the famous art historian Wölfflin's differentiation between renaissance and Baroque art, arguing "There [in the Renaissance] it is the defined shaped, here [in the Baroque] it is the changing appearance; there it is the continuing form, measurable and confined, here it is movement, form in function; there the things in themselves, here the things in their relationships" (Straus 1966, 31n6). The main argument is not that Baroque art is more pathic than Renaissance art, but that through techniques, visual art can overcome the gnostic mode of perceptual appearance characterized by separated visual representations and conceptual representations. Unlike our everyday vision in which the objects appear before the already constituted subject, visual art is the creation of a world that can "overcome apartness and distance and to create a second world by proclaiming the harmony of appearances" $(1966,17)$. Here, Straus does not write extensively on visual art, but one of the central aspects of the pathic dimension in visual space is to be found in his differentiation between geographical space and space of the landscape (1963). 
As he argues, geographical space is a "horizonless space" constituted by a system of coordinates in which our place is determined by position in relation to an arbitrary null point of a closed system. Straus contends that, as soon as we use a map or ask for directions to orient ourselves, we establish our place outside of a horizon. We empty the space by distancing ourselves from the lived moment of the surroundings in which we are immersed. The space of the landscape, however, relates to a different aspect of time or temporality, based on the direct and perpetual movement or unfolding of the now, rather than time as an extension in space. It is in this context of the temporality of the perpetually and directly unfolding sensory world that rhythm is given a constitutive role in Straus's work. Just as in Husserl's analysis of time consciousness, the central question is how a temporally unfolding phenomenon accomplishes a qualitative unified structure of subjective experience. According to Straus, this level of temporal formation belongs to the presubjective level of sensing. In relation to Husserl's own words, sensing in Straus amounts to the "affectively binding force for consciousness." However, where Husserl's analysis ends with the acknowledgment of a pre-empirical affective or pathic unification in time consciousness, Straus's effort is more directly proposing rhythm as the affectively binding force for phenomenological time consciousness. Transferred to the notion of the landscape in visual experience, this description would suggest that rhythm also becomes the aspect that constitutes the affectively binding fullness and unification of the temporal unfolding in the experience of a visual object like a painting. Although Straus does not go further into this pathic dimension of the visual in art, it is the French phenomenologist Henri Maldiney who more thoroughly develops Straus's notion of rhythm and the pathic moment in relation to visual art.

\section{MALDINEY AND THE AESTHETICS OF RHYTHM}

As already mentioned, Straus's association of the pathic dimension with music and dance does not mean that the visual is purely a perceptual or gnostic phenomenon devoid of a sensory emergent aspect. As Maldiney argues, Straus's paradigmatic discrepancy of visual and auditory objects is justified in terms of the practical value of the senses - that is, to exemplify the difference between pathic and perceptual experiences-but it does not oppose the question of the sensory unity of the emergent visual object. Beyond its perceptual appearance, color is, just as sound, a sensory given which cannot be reduced to a phenomenon separated from its emergent qualities. While Straus's exemplification of the pathic dimension emphasizes the qualities of distance and separation in the appearance of visual objects in opposition to the pathic unity of experiences of sound, Maldiney points out that Straus's analysis of the emergent unity of the senses holds true also for the experience of visual objects in art. Consequently, to Straus's comment that "[c]ontour separates things from things; accord binds sound to sound" (1963, 376), Maldiney adds, "But in painting the accord binds form to form" (2012b, 195). According to Maldiney, visual art cannot be reduced to its perceptual givens but must be understood as an emergent phenomenon that unifies forms. In this sense, the experience of visual art is not simply the subjective encounter with a static object or a collection of colors and forms but is rather an opening of pre-reflective processes of emergence of color and formation. Aesthetic experience with visual art concerns the actual and fundamental sensuous creation of space and time. As the fundamental constituents of our perceptual world, space and time cannot simply be considered conditions for subjectivity but must themselves be explained. In other words, there is a truth in art that concerns the general notion of sensation that cannot be subjugated to time and space as a general condition of possibility for sensation. The encounter with a work of art amounts to a sensuous manifestation of the subject in its simultaneous unfolding actualization of the world. Here, the aesthetic experience is an animation of the unfolding of the fundamental I-world relationship, which is not the same as a subject-object relation. The aspect of rhythm in experience does not concern a world of objects from which the artist and the work of art take up a motive or theme. Rather, the work of art must create its own world, and, in this context, the aesthetic or rhythmic aspects concern the relational constitution of the experiential world and its subject in formation, never as already formed entities. Maldiney often refers to Cézanne's descriptions of becoming with, or inhabiting, the world of his paintings (2012b, 245, 293, 322), as 
when Cézanne describes the ideal of landscape painting as a creation of space where "man [is] absent from but entirely within the landscape" $(2001,119)$.

In line with Straus's account of the pathic dimension of sensing as a process of becoming with the world, Maldiney argues that colors and visual objects are not just there in front of us, but that they appear in dynamic processes of emergence ultimately involving the very unity of the senses - that is, the fundamental sensory constitution of subjectivity. It is this dynamic or emergent quality of experience and subjectivity that, Maldiney argues, visual art can manifest through the creation of rhythms. In support of this unifying quality of painting, he also refers to Straus's primacy of movement in the pathic dimension of music and dance. However, in Maldiney, this principle of the pathic moment is extended to be the central component of all art and the link to the notion of the landscape as the origin or emergence of space in all arts. Consequently, to Maldiney, Straus's notion of the space of the landscape does not only apply to landscape painting, but to all painting and ultimately to all art. Accordingly, the experience of visual art shares the same primacy of phenomenological time, movement, and the pathic moment with music or dance and thus unfolds entirely within the space of the landscape, in which we are lost outside the distanced and separated orientation of extended or geographical space. However, as Maldiney argues, this does not mean that experiences with paintings are simply a type of losing track of extended time or introspective daydreaming. Rather, visual art is, as he writes, "another way of waking us up from being lost without leaving the landscape" (2012b, 197).

Visual art, according to Maldiney, is thus an opening of the existential conditions of our sensuous being. It is not what is given to subjective experience as recognition. It works through the unexpected, as that by which the given is given. As he adds, "The real is what one does not expect, and which yet is always already there" (2012b, 207). The unexpected, as an ever present differential aspect of sensing, amounts to a revelatory phenomenon in art and aesthetic experience. In this context, rhythm becomes a central aesthetic concept in the broad sense of aesthesis, capturing the experiential capacity for integrating the chaotic foundation of sensing in unexpected aspects of surprise, change, and movement in our perceptual being. Rhythm thereby expresses the temporal aspect immanent to lived experience. Following philosopher Richard Hönigswald's definition of rhythm as the articulation of time by time, or the temporal articulation of time, Maldiney argues that rhythm is where the living and the lived become one in a self-organizing process. On this account, rhythm is not simply the order of time, because, as Maldiney maintains, "It is not enough that the articulating moments constitute an order, this order also has to carry a temporal dimension" (2012b, 215). In other words, the temporal dimension cannot be considered as a given but must have a generative aspect, or rather an autogenerative or self-organizing aspect. Transferring this self-organizing principle to paintings, Maldiney argues that a figurative form has two dimensions, one intentionally representative, in which the painting is an image; the other "generative-rythmic" [fr. génétiquerythmique], which is the act of the form or the act "by which a form takes its form-its autogenesis" (2012b, 211). Borrowing from the linguist Gustave Guillaume and philosopher Henri Bergson, Maldiney argues that the rhythm of a form is the articulation of its "implied time." Consequently, as opposed to Husserl's notion of time consciousness as the qualitative unity of the extended continuity of time, Maldiney's notion of aesthetic experience as a rhythmicity of implied time is not a question of intentionality, because time, according to Maldiney, is not something given but is wholly aesthetically created with the unfolding now of sensing and with this the emergence of subjectivity.

The aesthetic experience is not, in the Husserlian sense, an intentionality. In fact, the consciousness, or rather the presence of the spectator or listener of a work of art, does not have any other constitutive structures than the ones of the work of art. (Maldiney 2012b, 186-187)

In this sense, the implied time is the tension or intensity immanent to the duration, which creates a temporal quality or dimension. On this account, Maldiney's accomplishment is to take this argument and show how implied time is not only a phenomenon in the formation or emergence of sound but is also the formation of color. Thus, time in a painting is not given; it is genuinely 
created or composed through the process by which the forms become forms.

VII RHYTHM AS HISTORICAL AND PICTORIAL

Maldiney finds primary sources of support for his argument in his analysis of different artists, including the artists' own descriptions of their work as well as art historical resources from classical scholars such as Alois Riegl and Wilhelm Worringer. Maldiney argues that rhythms constitute the foundation of the characteristics of the different art historical periods or époques. Rhythm, as different expressions of temporality, is here actualized as different styles in the history of painting. As an example, Maldiney refers to the parietal wall paintings of Lascaux, which appear as gestural sketchings of the momentary and emergent dynamic appearances of animals to the hunters. However, as Maldiney argues, this emergence of appearance is not simply preserved as a snapshot of the moment in extended time, but it is presented in a particular rhythm of formation that gives the paintings a quality or dimension of the unfolding now of lived existence. The forms of the animals are, in their quality of appearance, one with the complete intermodal sensuous environment of the hunter, that is, the hunter being on guard, attentively listening to his environment or his Umwelt (Maldiney 2012b, 192).

Precisely because rhythm is an amodal aspect of sensing (not belonging to one particular sense modality), the rhythm in visual art cannot be reduced to formal or objective qualities of the visual modality. Rather, it expresses the rhythmic unifying of all the senses in the process of seeing. "A rhythm is unobjectifiable. ... It can only be lived" (Maldiney 2012a, 307). Being moved by an aesthetic experience of a painting is a lived process of rhythmic unification that involves the taking shape of our own perceptual or affective being. In this sense, seeing a painting becomes a seeing with or according to the painting. According to Maldiney, this is also the reason why we can discern particular styles of different art historical periods or époques, because they express different existential and temporal conditions for sensing. Drawing on the art historian Alois Riegl, the style of forms of the different art historical époques reflects a particular Kunstwollen. ${ }^{1}$ Beyond the differences in styles, rhythm as an existential aspect of the senses traverses the history of art. In the parietal wall paintings, what is recognized, or what resonates across space and time, is not only a formal composition or objective representation of animals in the visual domain, which tells us something about the hunters' existence 17,000 years ago. It also expresses the fundamental rhythmicity of seeing as a cross-modal dynamic event, which also gives the paintings vitality and presence to contemporary viewers. In this perspective, the history of art articulates a history of perception in the sense that the dynamic rhythms or formation immanent to the different style periods reveal or open different temporal qualities connected to fundamental conditions for visual cultures. Therefore, "[t]he moment in art differs according to style. Classical art, Baroque art, Chinese art of the Song dynasty do not have the same instant" (Maldiney 2012b, 193). However, across these different temporal conditions and dimensions, Maldiney also identifies what he considers to be fundamental recurrent rhythms of temporal qualities in the apparition of space in visual art across different historical times. That rhythm cannot be objectified does not mean that the most fundamental rhythms or temporal qualities cannot be actualized or lived across different historical conditions. In this context, Maldiney describes three fundamental styles of rhythm: the systolic, diastolic, and systolic-diastolic, which correspond to three temporal qualities of the pictorial creation of space that traverse the history of art. As in Riegl's art historical approach, these rhythms of appearance in art are closely connected to the communication between the senses.

For example, the systolic is associated with what Riegl defined as the tactile or haptic vision, in which the composition gives us an experience of touch through vision and by this, a quality of an impenetrable or absolute appearance and a visual quality of being in front of an object. As Maldiney explains, the true sense of frontality is "that the work of art structures space around it by keeping us here-here where it gives itself fullywithout possibility of displacement. ... A closed rhythm of planes connected to figures shapes an absolute space" (2012b, 227). Maldiney mentions this absolute or closed rhythm as the first great rhythm in the history of art, which could be read as a support for Riegl's claim that the history of 
art began with the transition of three-dimensional space onto two-dimensional surfaces (Riegl 2000; Gubser 2006; Riegl 1923). As examples of this style or rhythmicity, Maldiney mentions sacred Egyptian and ancient Greek art, such as the Grave Stele of Ktesilaos and Theano (ca. 379 BC).

The diastolic rhythm is associated with Riegl's notion of optic vision, in which color, light, and shadow are dominating to create appearances that, according to Maldiney, manifest themselves through the opening of phenomena through their disappearance, for example, when a mountain appears through its disappearance in a mist or in landscape paintings where earth and sky are not simply connected by a reflection but are both partaking in a single autogenesis of space. As exemplary of the diastolic, he mentions Chinese paintings from the Song dynasty; Dutch landscape paintings, such as the work of Jan Van Goyen; and, lastly, "the impressionist tonality" (Maldiney 2012b, 206) in paintings by Cézanne, Van Gogh, and Seurat.

The third great rhythm, which Maldinely terms "systolic-diastolic," is the metamorphosis of appearance and disappearance as it is experienced in Baroque art, such as the work of Rubens, and in the sixth-century mosaics of the life of Christ in the Church of Sant'Apollinare Nuovo, Ravenna, Italy, or in some of Cézanne's aquarelles. As Maldiney describes, here rhythm manifests space as a perpetual movement between appearance and disappearance. In this "art of the passage" or attempt to capture pure perpetual movement, the reception of the world in an instant that makes up the temporal quality of presence is at one and the same time an abandonment and assemblage of space. According to Maldiney, "Space escapes itself in a diastole but the focus of the work of art assembles it in a systole, according to an expansive and contracting rhythm in modulation" (2012b, 228).

As already mentioned, common to all these expressions of rhythm is that they cannot be objectified. Thus, the history of painting is not the continuous revelation of different styles of objects, but rather a rendering of the rhythms of sensing immanent to objects of perception. Maldiney also calls this a progressive reduction of the "facticity of the object" through the successive styles of the époques. For example, Maldiney illustrates this process through comparing one of Cézanne's landscape paintings of the Sainte-Victoire mountain in Aix-en-Provence with a nineteenth-century lithograph of the same motive. In Cézanne's rendering of the mountain, many objective details are omitted compared to the more conventional lithograph. According to Maldiney, what is left in Cézanne's rendition is the dynamic vitality of the mountain's abrupt appearance, rather than the dead representations of the location. In this sense Cézanne's rendition illustrates Straus's fundamental differentiation of the space of geography and landscape as Maldiney describes Cézanne's painting, "the mountain is not situated in the landscape, it is the landscape" (2012a, 24). In Cézanne's painting, Maldiney describes the abrupt appearance of the mountain as the result of the layering folds of dark shadows in rhythmical exchange with an exploding light in the discontinued distributed clear spots. In this sense, rhythm at the pictorial level unifies the simultaneity of the mutual tension between differential elements of dark folds and clear spots in the painting. Thus, in relation to Straus's notion of the landscape as being lost, Maldiney argues that rhythm is the only way to remain in the landscape without being lost. Accordingly, Maldiney's notion of the pictorial aspect of rhythm remains a purely experiential, qualitative, and descriptive characteristic throughout. Thus, the qualitative notions related to rhythm, such as systolic, diastolic, and implied time, rely primarily on the phenomenological descriptions of visual art by artists, art historians, and Maldiney's own experiences. However, beyond the purely descriptive level, the descriptions are further extended to fundamental ontological and existential aspects of sensation and the emergence of subjectivity. In this context, the qualitative notion of systolic and diastolic rhythms at the pictorial level are related to a fundamentally monadic understanding of the work of art as a world in itself, in which rhythm becomes the unifying aspect in the process of giving form to the dynamic and differential forces of sensation.

\section{CONCLUSION}

As we have shown in this article, rhythm can be considered a central phenomenon in aesthetic experience. Following Straus and Maldiney, rhythm appears as a pre-individual force that explains the becoming or the perpetual unfolding of subjectivity. The processual aspect of rhythm as 
related to the becoming of subjectivity in perpetual movement is instrumental to the explanation of why profound aesthetic experiences often directly move or affect the beholder. What moves us in a painting is not simply the perception of the work of art as an object, but the experience of something taking shape in the work of art. In this understanding, rhythm becomes central to what Straus considers a preconceptual mode of communication between the sensing subject and the world taking shape in color and line. To experience a painting aesthetically is to be absorbed in a rhythm of dynamic emergence that involves the constitution of one's own sensing being in the composition. Thus, rhythm as immanent to sensation is not a mode of visual knowing or recognition, it is a preconceptual mode of responsivity in the communication between the different senses encountering the world. On this account, the rhythm immanent to aesthetic experience in visual art can be described as the responsivity to a temporal domain that actualizes simultaneously with the viewer's perceptual and affective absorption in the work of art. Following Maldiney, it is the rhythm of implied time in Cézanne's composition of Sainte-Victoire that immerses us in the unified lived experience of being in the unfolding now of the landscape. In this sense, aesthetic experience of the landscape exceeds the visual sense modality through the rhythm that traverses and unifies all the modalities. We do not simply see the landscape, but through the common sensible of rhythm we experience it with all our senses. It is not the extended rhythm of a subject in front of an object, but a rhythmic co-presence of the work of art and subjective sensibility emerging from the same process. The absorption in the rhythm in visual art works as a removal of the distancing movement of temporal extension to reach an experience of intense qualitative depth in the unfolding now. It is through the rhythmic intensity of composition that visual works of art can create new sensations by inviting the subject to experience a world directly and completely on the premises of the composition. How this process of establishing "a world" works is a matter of composition in color and line, but the composition gets its unity from the unobjectifiable rhythm immanent to it. In this sense, the modernist artist's inspirations in musical rhythm should not be considered as attempts to represent the sequentially extended rhythm in music but to explore the experience of a temporal intensity through a compositional unification of differential forces of sensation. ${ }^{2}$

KASPER LEVIN ID AND TONE ROALD

Department of Psychology

University of Copenhagen

1353 Copenhagen, Denmark

INTERNET: kasper.levin.jensen@psy.ku.dk,

tone.roald@psy.ku.dk

\section{BJARNE SODE FUNCH}

Department of Psychology and Educational Studies

Roskilde University

DK-2300 Roskilde, Denmark

INTERNET: bfunch@ruc.dk

\section{REFERENCES}

Barbaras, Renaud. 2004. "Affectivity and Movement: The Sense of Sensing in Erwin Straus. Phenomenology and the Cognitive Sciences. Translated by Elizabeth A. Behnke.3: 215-228. https://doi.org/10.1023/B:PHEN.0000040834.95059.0a.

Cézanne, Paul. 2001. Conversations with Cézanne, edited by Michael Doran. University of California Press.

Fry, Roger Eliot. 1951. French, Flemish and British Art. New York: Coward-McCann.

Gaiger, Jason. 2018. "Can a Painting Have a Rhythm?" British Journal of Aesthetics 58: 363-383. https://doi.org/10. 1093/aesthj/ayy026.

Gubser, Mike. 2006. Times Visible Surface: Alois Riegl and the Discourse on History and Temporality in Fin-de-Siècle Vienna. Wayne State University Press.

Husserl, Edmund. 1991. On the Phenomenology of the Consciousness of Internal Time (1893-1917), edited by Rudolf Bernet. Translated by John Barnett Brough. Dordrecht: Kluwer Academic Publishers.

. 2001. Analyses Concerning Passive and Active Synthesis: Lectures on Transcendental Logic, edited by Rudolf Bernet. Translated by Anthony J. Steinbock. Dordrecht: Kluwer Academic Publishers.

Kandinsky, Wassily. [1914]1977. Concerning the Spiritual in Art. Translated by M.T.H. Sadler. New York: Dover.

Klee, Paul. 1961. Paul Klee Notebooks: Volume 1: The Thinking Eye, edited by Jürg Spiller. Translated by Ralph Manheim. London: Lund Humphries.

Maldiney, Henri. 2012a. L art, léclair de lêtre. Paris: Éd. du Cerf.

. 2012b. Regard, Parole, Espace, edited by Christian Chaput, Philippe Grosos, and Maria Villela-Petit. Paris: Les Éd. du Cerf.

Riegl, Alois. 1923. Stilfragen: Grundlegungen Zu Einer Geschichte Der Ornamentik. Second edition. Berlin: Schmidt Company.

Riegl, Alois. 2000. Spätrömische Kunstindustrie. Berlin: Gebr. Mann Verlag.

Rutherford-Johnson, Tim, Michael Kennedy, and Joyce Bourne Kennedy. 2013. "Rhythm." In The Oxford Dictionary of Music, edited by Tim Rutherford-Johnson. Oxford University Press. https://doi.org/10.1093/acref/9780199578108.001.0001. 
Straus, Erwin. 1963. The Primary World of Senses: A Vindication of Sensory Experience. Translated by Jacob Needleman. New York: Free Press of Glencoe.

. 1965. "The Sense of the Senses." Southern Journal of Philosophy 3: 192-201.

- 1966. "The Forms of Spatiality." In Phenomenological Psychology: The Selected Papers of Erwin W. Straus, translated by Erleing Eng, 3-38. New York: Basic Books.

Whittall, Arnold. 2011. "Rhythm." In The Oxford Companion to Music, edited by Alison Latham. Oxford University Press. https://doi.org/10.1093/acref/9780199579037.001.0001.

Williams, C. F. Abdy. 1911. Aristoxenian Theory of Musical Rhythm. Cambridge University Press.

Wölfflin, Heinrich. 1950. Principles of Art History: The Problem of the Development of Style in Later Art. Translated by M. D. Hottinger. New York: Dover.
Zahavi, Dan. 2010. "Inner (Time-) Consciousness." In On Time-New Contributions to the Husserlian Phenomenology of Time, edited by Dieter Lohmar and Ichiro Yamaguchi, 319-339. Dordrecht: Springer.

1. Riegl (2000) developed the notion of "kunstwollen" in opposition to the common conception promoted by the German architect and art critic Gottfried Semper, who argued that art or aesthetic forms developed and were determined purely from material, technical, and utilitarian goals and practices.

2. Research for this article was supported by the Independent Research Fund, Denmark, under grant number DFF-6107-00273. 